\title{
O uso do camalote, Eichhornia crassipes (Mart.) Solms, Pontederiaceae, para confecção de artesanato no Distrito de Albuquerque, Corumbá, MS, Brasil ${ }^{1}$
}

\author{
Ieda Maria Bortolotto ${ }^{2,4}$ e Germano Guarim Neto ${ }^{3}$
}

Recebido em 16/12/2003. Aceito em 24/09/2004

\begin{abstract}
RESUMO - (O uso do camalote, Eichhornia crassipes (Mart.) Solms, Pontederiaceae, para confecção de artesanato no Distrito de Albuquerque, Corumbá, MS, Brasil). Eichhornia crassipes (Mart.) Solms, conhecida localmente como camalote, é uma planta aquática nativa da América do Sul, abundante no Pantanal. Os índios Guató usavam essa planta no Pantanal para a confecção de esteiras para dormir. Atualmente a comunidade não indígena do distrito de Albuquerque, Corumbá, MS, está fazendo artesanato com essa planta. O processo foi ensinado por uma índia Guató (74 anos) que manteve a tradição de trançar o camalote. O uso do camalote para a confecção de artesanato é descrito aqui. O método utilizado inclui entrevistas semi-estruturadas e observação participante. A extração do camalote é feita nos rios, corixos e lagoas da região. As folhas são cortadas e somente os pecíolos são transportados para casa, lavados em água corrente e colocados para secar ao sol. Depois de secos os pecíolos são trançados e costurados. A técnica original dos Guató consiste em costurar o artesanato com linhas confeccionadas com algodão (Gossypium sp.) ou tucum (Bactris sp.), atualmente substituídos por fios de nylon, em Albuquerque. O artesanato é vendido aos turistas.
\end{abstract}

Palavras-chave: camalote, aguapé, extrativismo, atividade econômica, Etnobotânica

\begin{abstract}
The use of the camalote, Eichhornia crassipes (Mart.) Solms, Pontederiaceae, for handicraft in the District of Albuquerque, Corumbá, MS, Brazil). Eichhornia crassipes (Mart.) Solms, known locally as camalote, is an aquatic plant indigenous to South America, abundant in the Pantanal, Brazil. Guató Indians used it for making sleeping mats in the Pantanal. The non-Indian community of Albuquerque, Corumbá, MS, nowadays, is also using it for the same purposes. An ancient Guató Indian 74 years old taught the process. The use of the camalote for handicraft in Albuquerque is described here. The methods of investigation included both semi structured interviews and participant observations. The extraction of the camalote is made on the rivers, corixos and lagoons of the area. The leaf blades are cut and only petioles are carried to the houses, washed in clear water, and dried in the sun. After dried, the petioles are woven and sewed. The Guató original technique consists of sewing the craft with threads made of cotton fibers (Gossypium sp.) or tucum fibers (Bactris sp.) recently replaced by a nylon thread in Albuquerque. The crafts are sold to tourists.
\end{abstract}

Key words: camalote, water hyacinth, extractivism, economical activity, Ethnobotany

\section{Introdução}

Eichhornia crassipes (Mart.) Solms, conhecida no Pantanal como camalote, é uma planta aquática, flutuante, anual ou perene, nativa da América tropical. O caule flutuante é rastejante e forma estolões. O pecíolo pode ser ocasionalmente inflado. As flores têm pétalas lilases com margem lisa e uma mancha amarela na pétala superior. São dispostas em espigas e flores ocorrem quase o ano todo. O camalote se reproduz vegetativamente por estolões e por sementes que são dispersas pela água e possui capacidade de regeneração muito rápida (Gopal 1987; Cook 1990; Pott \& Pott 2000).

Eichhornia crassipes foi introduzida na maior parte das regiões quentes e tropicais dos continentes no final do século XIX com fins ornamentais, tendo causado nessas regiões sérios problemas ambientais (Corrêa 1926). Foi considerada como "perigo público” em muitos países, onde causou o entupimento de cursos d'água impedindo a navegação e promovendo a eutrofização de represas e lagos. Além da eutrofização

1 Parte da Dissertação de Mestrado da primeira Autora; apoio CAPES

2 Universidade Federal de Mato Grosso do Sul, UFMS, Departamento de Ciências do Ambiente, Campus de Corumbá, C. Postal 252, CEP 79304-020, Corumbá, Mato Grosso do Sul, Brasil. Bolsista PICD/CAPES

3 Universidade Federal de Mato Grosso, Instituto de Biociências, Departamento de Botânica e Ecologia, Av. Fernando Correia da Costa, s/n, Cuiabá, Mato Grosso, Brasil

4 Autor para correspondência: iedamaria@terra.com.br 
Pedralli et al. (1993) destacaram entre os impactos negativos de populações de Eichhornia crassipes e Eichhornia azurea em reservatórios, a obstrução de tomada d’água e a formação de hábitats propícios ao desenvolvimento de vetores de doenças de veiculação hídrica.

Apesar dos problemas causados nos locais onde foi introduzida, essa espécie tem sido aproveitada para diversos fins, como alimentação de animais, construção de armadilhas de peixes, adubos para a agricultura, medicinal, produção de papel, controle da poluição da água e produção de energia (Biogás), valor ornamental e ecológico, servindo de hábitat para diversos organismos aquáticos, além de ser usada para confecção de esteiras, cordas, cadeiras, cortinas e outras obras trançadas (Corrêa 1926; Medina 1959; Gopal 1987; Pott \& Pott 2000). A National Academy of Sciences (1976) relatou o início do uso de Eichhornia crassipes nas Filipinas para confecção de cestas e bolsas e descreveu brevemente o processo de coleta e secagem dos pecíolos usados como matéria-prima.

O uso de fibras de origem vegetal para a confecção de artesanatos no Brasil está associado a culturas indígenas que desenvolveram técnicas de secar, trançar e costurar, com vários estilos diferentes. Ribeiro (1987) e O’Neale (1987) descreveram várias técnicas, tipos de trançado e citaram produtos de diversas famílias botânicas, principalmente palmeiras (Arecaceae). Oliveira (1996) citou vários tipos de tecelagem e trançados com palmeiras pelos índios Guató no Pantanal brasileiro. O uso do camalote (Eichhornia crassipes) não é mencionado nesses trabalhos e não há descrição sobre o processo de coleta e confecção do artesanato. Apesar de ser planta originária da América do Sul, o único registro encontrado sobre o uso dessa espécie para produção de artesanato no continente de origem é de Ramires (1987), em matéria jornalística sobre a etnia Guató no Mato Grosso do Sul.

Este estudo é parte de um projeto maior, que teve como um dos objetivos resgatar informações sobre o uso de plantas no distrito de Albuquerque, no Pantanal sul-mato-grossense. Durante o trabalho verificou-se o desenvolvimento do artesanato com Eichhornia crassipes, que vinha sendo produzido e comercializado há duas décadas no distrito, e como já mencionado, carecia de registro na literatura especializada. O objetivo principal deste trabalho foi conhecer e descrever o processo de extração e confecção do artesanato com Eichhornia crassipes no distrito de Albuquerque. Procurou-se também investigar a origem da utilização dessa planta para confecção de artesanato no Pantanal e levantar aspectos relacionados à sua comercialização.

\section{Material e métodos}

Área de estudo - Os estudos foram desenvolvidos na área urbanizada do distrito de Albuquerque, que pertence ao município de Corumbá, localizado a cerca de $60 \mathrm{~km}$ ao sul da sede. $\mathrm{O}$ distrito localiza-se à margem direita do rio Paraguai, no Pantanal sul-matogrossense.

As principais atividades econômicas do distrito sempre foram a pecuária extensiva, a pesca, a caça e a agricultura de subsistência. Na área urbana essa situação vem mudando nos últimos 20 anos e, atualmente, a principal atividade econômica está relacionada ao turismo de pesca, com grande desenvolvimento da coleta de iscas vivas como alternativa econômica.

O Censo do IBGE (1991) indicou 313 famílias e 1.304 pessoas que residiam no Distrito no início da década. Dessas, apenas 428 pessoas residiam na área urbana, em 98 domicílios. O número de habitantes na área urbana aumentou muito por causa da entrada do turismo de pesca na região, e o Censo do IBGE de 2000 contou 1.846 pessoas, das quais 919 residiam na área urbana, em 189 domicílios.

O principal rio coletor das águas da planície pantaneira é o Paraguai, que nasce nas encostas da serra dos Parecis, na região norte, e continua até o sul, na confluência com o rio Paraná (Carvalho 1986). O regime hidrológico do rio Paraguai é responsável por cheias anuais, que faz flutuar o nível da água na lagoa de Albuquerque e de rios e corixos menores que estão ligados a ele. Corixo é uma denominação local para curso d'água estacional com leito definido e mata ciliar descontínua (Pott \& Pott 2000). O rio Paraguai está no nível mais baixo em dezembro, quando tem início a enchente, que tem seu pico em abril, maio e junho. Depois disso, tem início a vazante até o mês de dezembro, quando as águas estão no seu nível mais baixo novamente (Galdino \& Clarke 1995).

Eichhornia crassipes (Fig. 1) é amplamente distribuída em rios, lagos e baías do Pantanal MatoGrossense. Sanches et al. (1999) citaram a presença dessa espécie formando imensos baceiros (termo local para denominar bancos de macrófitas aquáticas) que descem o rio Paraguai.

Procedimentos - Os dados foram coletados no período de junho a dezembro/1998 com visitas quinzenais à comunidade de Albuquerque. Os procedimentos de 
pesquisa incluem entrevistas semi-estruturadas e observação participante (Bernard 1988). Foram entrevistados cinco artesãos, sendo três do distrito de Albuquerque (duas mulheres e um homem) e duas artesãs na cidade de Corumbá. Dos entrevistados, duas mulheres foram consideradas informantes-chave (Bernard 1988) por demonstrarem excepcional conhecimento sobre o aproveitamento do camalote para artesanato. Celeste Dias da Silva, de 64 anos, considerada informante-chave no distrito de Albuquerque, era a única moradora que desenvolvia e comercializava seus produtos na comunidade durante o período de estudos, além de ensinar a técnica às crianças e jovens da escola rural do distrito. Essa moradora é reconhecida pela comunidade como detentora de grande conhecimento sobre o uso de plantas. Os outros dois entrevistados na comunidade auxiliavam essa artesã em atividades esporádicas.

Celeste Dias da Silva indicou para entrevista a índia Guató Josefina Alves Ribeiro (74 anos, publicamente reconhecida), com quem aprendeu a técnica. A índia Guató foi considerada informantechave na cidade de Corumbá, onde reside atualmente e foi entrevistada juntamente com sua filha, Rosa Alves Ribeiro, que também era artesã.

Para as entrevistas foram elaboradas listas com questões sobre o modo como os artesãos haviam aprendido a atividade de trançar o camalote, materiais utilizados durante o processo, tipos de trançado conhecidos, dificuldades encontradas e formas de comercialização dos produtos. As entrevistas foram anotadas e as etapas do processo de coleta e produção do artesanato foram registradas por meio de diapositivos e fotos em papel.

Durante o período de estudos foi organizada uma atividade envolvendo os alunos da escola municipal local, "Escola Polo Nathercia Pompeu dos Santos", que participaram das atividades de extração, preparo das fibras e confecção do artesanato. Nesse período, que durou uma semana, foi possível registrar e participar ativamente de uma seqüência completa da produção do artesanato.

A análise dos dados foi realizada por meio da comparação das informações obtidas nas entrevistas e durante o processo de observação participante, permeando o processo de investigação. À medida que os dados eram coletados, passavam por uma análise que gerava questões para serem verificadas na próxima etapa. Para testar a legitimidade dos dados, as informantes-chave conferiram os resultados onde o processo de confecção de artesanato é descrito.
Um exemplar de Eichhornia crassipes (Mart.) Solms foi coletado (número do coletor 679), herborizado e depositado no Herbário COR da Universidade Federal de Mato Grosso do Sul, Câmpus de Corumbá, com o registro № 7171.

\section{Resultados e discussão}

A origem do uso da fibra de camalote no Pantanal Mato-Grossense para tapeçaria está associada aos índios Guató, canoeiros do Pantanal, considerados extintos por longo período. Recentemente, membros de famílias que viviam na periferia de cidades do Pantanal foram instalados na ilha Ínsua, Mato Grosso do Sul.

Josefina Alves Ribeiro, descendente indígena Guató, manteve a tradição de trançar o camalote e confecciona tapetes que são comercializados em pequena escala na “Casa do Artesão” em Corumbá. Em entrevista a Ramires (1987), Josefina contou que aprendeu a trabalhar com as fibras de camalote com sua mãe e com a avó, no Aterro de Joaquim Ferreira, no Porto Conceição, Pantanal. Sua filha, Rosa Alves Ribeiro, também aprendeu a arte de trançar o camalote, mas não conseguia mais se manter com essa atividade, pois, segundo ela, a comercialização na Casa do Artesão era lenta e elas demoravam muito para receber o valor da venda.

Josefina, além de continuar com essa atividade, ministrou vários cursos em Corumbá em pequenas comunidades rurais da região. Um desses cursos foi realizado no Distrito de Albuquerque e teve duração de cerca de 30 dias. Diversas pessoas fizeram o curso, principalmente mulheres, que aprenderam a técnica, inicialmente apenas para confecção de tapetes. Muitos deixaram a atividade de lado nessa comunidade, mas Celeste Dias da Silva continuou a confecção de tapetes e outros objetos, juntamente com familiares e algumas artesãs.

O camalote é extraído dos cursos d'água da região em qualquer período do ano. No período de cheia do rio Paraguai fica mais macio, sendo melhor para os trabalhos manuais. Nesse período, quando as águas estão altas, a coleta é feita de canoa. Nos períodos mais secos o coletor entra na água que fica à altura do joelho.

O artesanato é feito com o pecíolo das folhas que são emergentes. As folhas são cortadas de indivíduos adultos com $50 \mathrm{~cm}$ ou mais. Os indivíduos jovens não são utilizados, assim como os que possuem o pecíolo inflado. O corte é feito com tesouras ou facas afiadas 
e com pequenos facões. Após o corte das folhas, os pecíolos são separados do limbo, que é descartado. Os pecíolos são colocados em grandes sacos plásticos para serem transportados.

Todo o preparo dos pecíolos do camalote é feito no quintal da casa, onde são lavados em água limpa e corrente. Depois de bem lavados, são espalhados sobre uma tela ou piso de cimento para desidratação ao sol (Fig. 2). À noite, o material deve ser recolhido para evitar a hidratação. No período de verão, quando a temperatura na região chega a $40{ }^{\circ} \mathrm{C}$, a secagem completa ocorre com três dias de exposição ao sol.

Quando os pecíolos estiverem bem secos, devem ser alisados com o auxílio de uma lâmina de metal; em seguida são separados em feixes e podem ser guardados por vários anos (Fig. 3). A coloração do pecíolo passa de verde a castanho claro, depois de seco. A base do pecíolo é mais grossa que o ápice, o que vai influenciar na maneira de trançar o camalote.

Para a confecção do artesanato são feitas, inicialmente, longas tranças. A trança é iniciada com três pecíolos, dois mais finos e um mais grosso, ou seja, dois ápices com a base do terceiro. Ao trançar, o pecíolo pode ser dobrado ou torcido.

Concluída uma longa trança, inicia-se a confecção do artesanato. São necessários em média $20 \mathrm{~m}$ de trança para confeccionar um tapete de $1 \mathrm{~m}$ diâm. Cada feixe com três pecíolos de $50 \mathrm{~cm}$, rende em média, uma trança de $30 \mathrm{~cm}$. São necessários, portanto, aproximadamente, três conjuntos de $2 \mathrm{~m}$ de pecíolos para produzir um metro de trança. Se forem aproveitados seis pecíolos de cada indivíduo de Eichhornia crassipes, seriam necessários dois indivíduos para a produção de 1,20 m de trança.

Após o artesão ter trançado vários metros de camalote, a trança é costurada começando com um caracol bem apertado (Fig. 4). A costura é feita com fios de nylon e as agulhas de costura são grandes $(10 \mathrm{~cm})$ e às vezes são improvisadas com sucata, como pequenas peças de guarda-chuvas, abridores de lata e outros.

No artesanato Guató não se usa o fio de nylon, e sim o de fibras vegetais. Antigamente eram utilizados fios tecidos das folhas de tucum (Bactris sp.), palmeira nativa das matas ciliares da região, ou de algodão (Gossypium sp.). As agulhas para costura também eram feitas com o tucum. Atualmente são usadas agulhas de metal.

Para a confecção do fio de tucum para costura, eram usadas as folhas da palmeira, de onde se retiravam longas fibras que eram deixadas de molho de um dia para o outro. No dia seguinte elas eram lavadas com água corrente e colocadas para secar. Os fios de algodão eram impermeabilizados com cera de abelha para ficarem mais resistentes. É interessante notar que Josefina até hoje impermeabiliza os fios de algodão (industrializados) com cera de abelha para costurar o trabalho vendido na Casa do Artesão de Corumbá.

Em Albuquerque fios de nylon são encontrados na margem dos rios, baías e corixos, deixados pelos pescadores. Para Rosa e Josefina, a costura feita com fios de algodão é melhor, pois com o nylon o ponto não fica firme, dificultando o trabalho. O uso dos fios de nylon, como o desenvolvido em Albuquerque, foi uma alternativa de baixo custo econômico. Para obter-se um produto original, com maior valor no mercado de artesanato, seria importante que os artesãos adotassem o uso do fio de fibras vegetais.

O desenho varia de acordo com a criatividade do artesão, mas grandes rodas são características dos tapetes (Fig. 5). No distrito de Albuquerque, além da produção de tapetes são confeccionados vários tipos de objetos como: porta latas, pequenos cestos para pães, bolsas, apoios para panelas e outros. A técnica de tecelagem também pode variar, se o artesão conhece outros padrões, como mostra a Fig. 6.

Na casa do artesão, em Corumbá, os tapetes Guató são vendidos por preços que variam de $\mathrm{R} \$ 20,00$ a $\mathrm{R} \$ 50,00$. Em Albuquerque o preço é menor e praticamente tudo que é produzido é vendido a turistas da região. O local de venda é a casa da artesã. Como não há transporte coletivo eficiente, fica difícil levar o artesanato para a cidade de Corumbá, na Casa do Artesão. Além do mais, a produção ainda é pequena e tudo que se produz é vendido rapidamente.

A comunidade de Albuquerque vive atualmente do turismo de pesca, que dura em média nove meses ao ano por causa do período de piracema. Nesse período, os trabalhadores ficam sem alternativas de trabalho e muitos têm seus contratos cancelados, passando por dificuldades financeiras. O trabalho com o camalote poderia ser uma fonte de renda alternativa para esse período na comunidade.

Interação com outra atividade extrativista - Para atender ao turismo de pesca, os pescadores profissionais têm se dedicado à coleta de iscas vivas no pantanal sul-mato-grossense (Fig. 7). Os trabalhadores que praticam essa atividade são chamados regionalmente de isqueiros. Entre as raízes do camalote, os isqueiros de Albuquerque encontram o caranguejo-vermelho (Dilocarcinus pagei) além de 
diversas espécies de pequenos peixes que são comercializados como isca para peixes maiores. Há vários questionamentos sobre a sustentabilidade da atividade devido, principalmente, à sobre-exploração das iscas e afetar a vegetação aquática. Atualmente a catação de isca é feita independentemente da coleta do camalote.

Durante o trabalho de catação de iscas, o camalote é revirado, formando um corredor de indivíduos “derrubados" de cerca 200 metros que podem ser explorados por mais uma semana, no máximo, para reaproveitamento de iscas que ainda persistem, sendo abandonados em seguida.

O esforço poderia ser otimizado se, tanto a isca como o camalote, fossem aproveitados. A extração do camalote para a confecção de artesanato seria importante se fosse consorciada com a "catação de iscas” e se os pecíolos fossem guardados para utilização
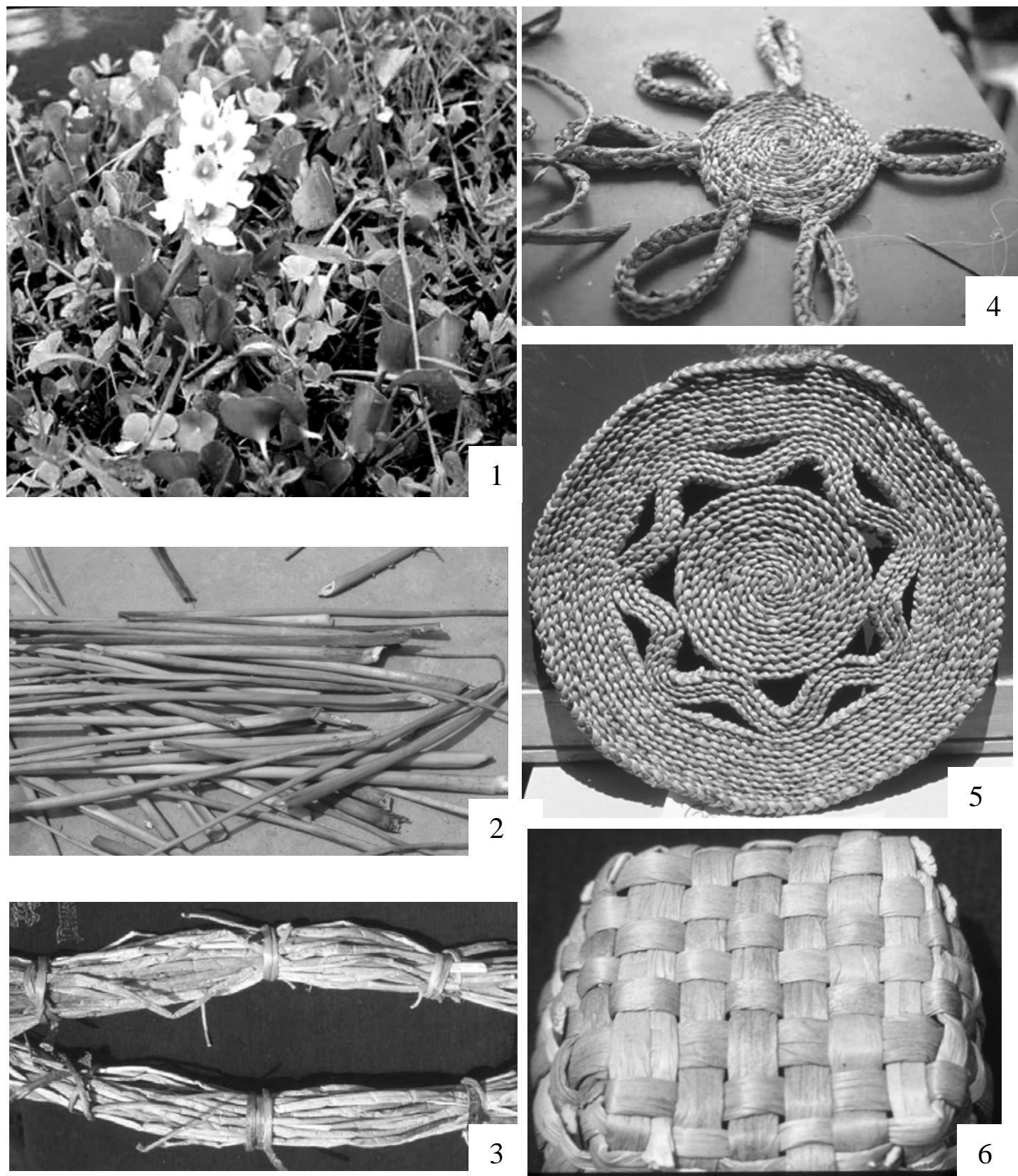

Figura 1. Aspecto geral da Eichhornia crassipes (Mart.) Solms. Figura 2. Pecíolos das folhas colocados para secar. Figura 3. Feixes de pecíolos secos. Figura 4. Montagem do artesanato com costura das tranças. Figura 5. Tapete confeccionado com o camalote. Figura 6. Detalhe de um cesto confeccionado com o camalote por artesãos de Albuquerque, Corumbá, MS, Brasil, usando outra técnica. 


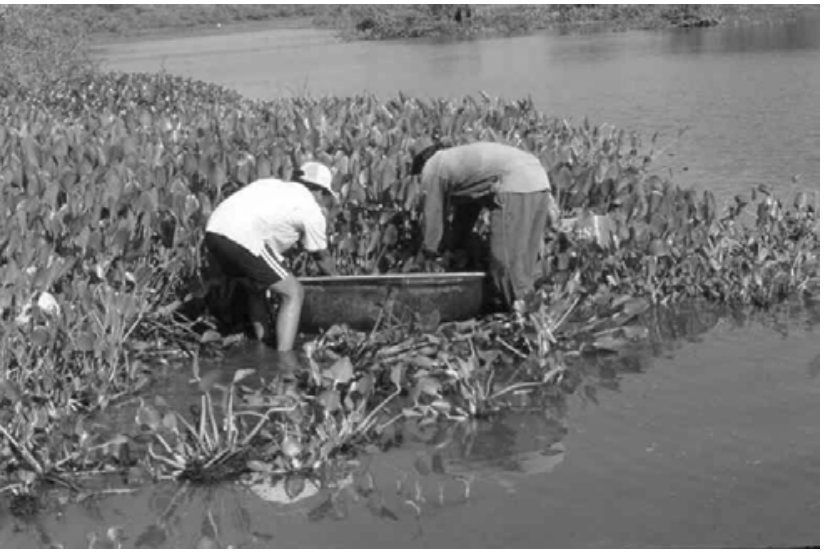

Figura 7. Coleta de iscas vivas sob o camalote na lagoa de Albuquerque, Corumbá, MS, Brasil.

no período de piracema. A utilização da fibra do camalote poderia ser uma alternativa econômica sustentável para as famílias da região. Seria importante também para diversificar as atividades de extrativismo e diminuir a pressão de captura das iscas vivas.

O consórcio dessas atividades, entretanto, merece especial atenção, uma vez que a "catação de iscas" ocorre em maiores proporções e implica na retirada não apenas do camalote, mas de diversas espécies a ele associadas. Por ser uma espécie nativa, Eichhornia crassipes oferece hábitat para muitos organismos aquáticos, além de servir de alimento para espécies de animais silvestres. A utilização do camalote para a confecção de artesanato é uma atividade recente para a comunidade de Albuquerque, assim como a atividade de "catação de iscas”. São necessários estudos na área de Ecologia (humana e de ecossistemas) para obtenção de resultados que auxiliem as comunidades a utilizarem os recursos de forma sustentável.

Durante o período de estudos, os alunos da escola municipal local, "Escola Polo Nathercia Pompeu dos Santos”, participaram das atividades de extração, preparo das fibras e confecção do artesanato com o camalote. Nessas atividades, que foram acompanhadas pelos artesãos e pelos professores da escola, foi possível iniciar um debate sobre a importância da atividade para a comunidade de Albuquerque e os possíveis impactos ao meio ambiente que estariam relacionados com a atividade extrativista. A participação da escola com o envolvimento dos alunos e o questionamento das conseqüências positivas e negativas com relação às atividades extrativistas é de extrema importância, uma vez que incentiva na comunidade o debate sobre o uso sustentável dos recursos.
Recentemente os índios Guató, que vivem na ilha Ínsua, receberam um curso sobre como trançar o artesanato. O curso foi ministrado pela índia Guató Josefina, por meio de um projeto desenvolvido pela organização não governamental ECOA (Ecologia e Ação), com sede em Campo Grande, Mato Grosso do Sul. Conhecer a técnica, entretanto, não garante a continuidade da atividade, que não está sendo desenvolvida pelos moradores da Ilha Ínsua. Por outro lado, o resgate do extrativismo de Eichhornia crassipes para a confecção de artesanato pela comunidade indígena, num período de tempo maior e com investimentos em projetos culturais nesse sentido, pode contribuir com o processo de reestruturação cultural da comunidade Guató.

O resgate desse conhecimento é uma demonstração de como os estudos etnobotânicos e a manutenção do conhecimento tradicional podem ser utilizados por comunidades humanas que necessitam ainda dos recursos do ambiente natural para sua sobrevivência.

\section{Agradecimentos}

Somos gratos à Celeste Dias da Silva, que teve paciência para ensinar todas as etapas de coleta, preparo e confecção de artesanato com o camalote; à Josefina Alves Ribeiro e à sua filha, Rosa Alves Ribeiro (in memorian), pelas valiosas informações; à Vali Joana Pott e Andréa da Luz Sanches, por disponibilizar bibliografia; ao Geraldo Alves Damasceno Júnior, à Iria Hiromi Ishii e à Maria de Fátima Silva-Almeida, pela leitura do texto e sugestões apresentadas; aos dois revisores anônimos, pelas correções e recomendações.

\section{Referências bibliográficas}

Bernard, H.R. 1988. Research methods in cultural anthropology. Newbury Park, CA, Sage Publ.

Carvalho, N.O. 1986 Hidrologia da Bacia do Alto Paraguai. Pp. 43-49. In: Anais do simpósio sobre recursos naturais e sócio-econômicos do Pantanal: manejo e conservação. Corumbá, 1986. Brasília, EMBRAPA.

Cook, C.D.K. 1990. Aquatic Plant Book. Netherlands, SPB Academic Publishing.

Corrêa, M.P. 1926. Diccionario das plantas uteis do Brasil. v.1. Rio de Janeiro, Ministério da Agricultura.

Galdino, S. \& Clarke, R.T. 1995. Levantamento e estatística descritiva dos níveis hidrométricos do rio Paraguai em Ladário, MS - Pantanal. Período 1900-1904. Corumbá, EMBRAPA/CPAP, 72 p. (Documentos, 14). 
Gopal, B. 1987. Water Hyacinth. Netherlands, Elsevier Science Publishers B.V.

IBGE. 1991. Censo Demográfico 1991: Mato Grosso do Sul. Rio de Janeiro, Instituto Brasileiro de Geografia e Estatística.

IBGE. 2000. Censo Demográfico 2000: Mato Grosso do Sul. Rio de Janeiro, Instituto Brasileiro de Geografia e Estatística.

Medina, J.C. 1959. Plantas fibrosas da flora mundial. Campinas, Instituto Agronômico.

National Academy of Sciences 1976. Making aquatic weeds useful: some perspectives for developing countries. Report of an Ad Hoc Panel of the advisory Committee on Technology Innovation Board on Science and Technology for International Development. Washington D.C., Commission on International Relations.

O’Neale, L. 1987. Cestaria. Pp. 323-349. In: D. Ribeiro (ed.). Suma etnológica brasileira. 2 ed., v.II., Petrópolis, Vozes.

Oliveira, J.E. 1996. Guató: argonautas do Pantanal. Porto Alegre, EDIPUC RS.
Pedralli, G.; Meyer, S.T.; Teixeira, M.C. \& Stehmann, J.R 1993. Levantamento dos macrófitos aquáticos e da mata ciliar do reservatório de Volta Grande, Minas Gerais, Brasil. Iheringia, série Botânica 43: 15-28.

Pott V.J. \& Pott. A. 2000. Plantas aquáticas do Pantanal. Embrapa. Centro de Pesquisa Agropecuária do Pantanal (Corumbá - MS). Brasília, Embrapa Comunicação para Transferência e Tecnologia.

Ramires, M. 1987. A volta de maguató - o frango d’água pantaneiro. MS CULTURA. Ano III - N. 7 - Março de 1987.

Ribeiro, B. 1987. A arte de trançar: dois macroestilos, dois modos de vida. Pp. 283-313. In: D. Ribeiro (ed.). Suma etnológica brasileira. 2 ed., v.II., Petrópolis, Vozes.

Ribeiro, B.G. 1987. Artes têxteis indígenas no Brasil. Pp. 351-375. In: D. Ribeiro (ed.). Suma etnológica brasileira. 2 ed., v.II., Petrópolis, Vozes.

Sanches A.L.; Bortolotto, I.M. \& Damasceno Júnior, G.A. 1999. Levantamento florístico das macrófitas aquáticas do rio Paraguai em Corumbá e Ladário - MS. Pp. 407-412. In: Anais do II Simpósio Sobre Recursos Naturais e Sócio-Econômicos do Pantanal: Manejo e Conservação. Corumbá, 1996. Brasília, EMBRAPA, 